\title{
A double-blind trial of hypogastric nerve block for postoperative pain relief following laparoscopic excision of endometriosis
}

Published online: 4 December 2004

(C) Springer-Verlag Berlin / Heidelberg 2004

\begin{abstract}
Pre-sacral or sacral plexus nerve blocks are reported in the anaesthetic literature as effective in controlling pelvic pain, but are rarely performed as they are technically difficult. The pre-sacral space, however, is easily assessable at laparoscopy, and it seemed that infiltration of local anaesthetic solution into this space might offer good pain relief for women undergoing operative laparoscopic procedures for endometriosis when there is destruction of the parietal peritoneum and in whom postoperative pain control, particularly in a day case environment, can prove difficult. Following an initial favorable report of procedure, preliminary clinical studies suggested that the procedure was safe and effective with apparently lower analgesia requirements in the immediate postoperative period. In order to evaluate this more systematically, a double-blind trial was undertaken comparing pre-sacral nerve blocks using chirocaine $(10 \mathrm{ml} \mathrm{0.5 \% )}$ against placebo $10 \mathrm{ml} 0.9 \%$ saline.
\end{abstract}

Keywords Hypogastric · Pain control · Pre-sacral

\section{Introduction}

Pre-sacral or sacral plexus nerve blocks are reported in the anaesthetic literature as effective in controlling pelvic pain, but are rarely performed as they are technically difficult. The presacral space, however, is easily assess-

There were no competing interests.

J. T. Wright $(\bowtie)$

Woking Nuffield Hospital,

Shores Road Woking, Surrey, GU21 4BY, UK

e-mail: jwrighta@cix.co.uk

B. J. Whitlow · R. Maher · J. T. Wright

Ashford and St Peter's NHS Trust,

Guildford Road, Chertsey, Surrey, KT12 OPD, UK

D. Lovell

Medical Department,

University of Surrey,

Surrey, UK able at laparoscopy, and it seemed that infiltration of local anaesthetic solution into this space might offer good pain relief for women undergoing operative laparoscopic procedures for endometriosis when there is destruction of the parietal peritoneum and in whom postoperative pain control, particularly in a day case environment, can prove difficult. Following an initial favorable report of the procedure [1], preliminary clinical studies [2] suggested that the procedure was safe and effective with apparently lower analgesia requirements in the immediate postoperative period. In order to evaluate this more systematically, a double-blind trial was undertaken comparing pre-sacral nerve blocks using chirocaine $(10 \mathrm{ml} 0.5 \%)$ against placebo $10 \mathrm{ml} 0.9 \%$ saline.

\section{Material and methods}

Women undergoing laparoscopic procedures for the excision of peritoneal endometriosis both in the private sector and the NHS were recruited for the study. Following informed consent they were allocated to receive either $10 \mathrm{ml}$ of $0.5 \%$ chirocaine or $0.9 \%$ saline injected through a spinal needle into the presacral space at the end of the procedure. Block randomisation in groups of ten was undertaken in the pharmacy and the appropriate solution prepared in a pre-loaded syringe for administration following the procedure. Women were asked to complete a visual analogue score at halfhour intervals for $4 \mathrm{~h}$ following the procedure and a pain assessment was also made by the attending recovery nurse. Women who complained of severe pain were offered rescue analgesia in the form of intravenous morphine $10 \mathrm{mg}$. Analysis was carried out using a sequential design, using Bross plan A.

\section{Results}

Twenty-eight women, 20 from the private sector and 8 from the NHS, were recruited into the study, resulting in 14 pairs. The sequential plan (Fig. 1) showed a slight preference toward placebo with little chance of a favourable clinical outcome, so the trial was abandoned as there was no clinical advantage in the technique. Intravenous morphine, however, was extremely effective in 


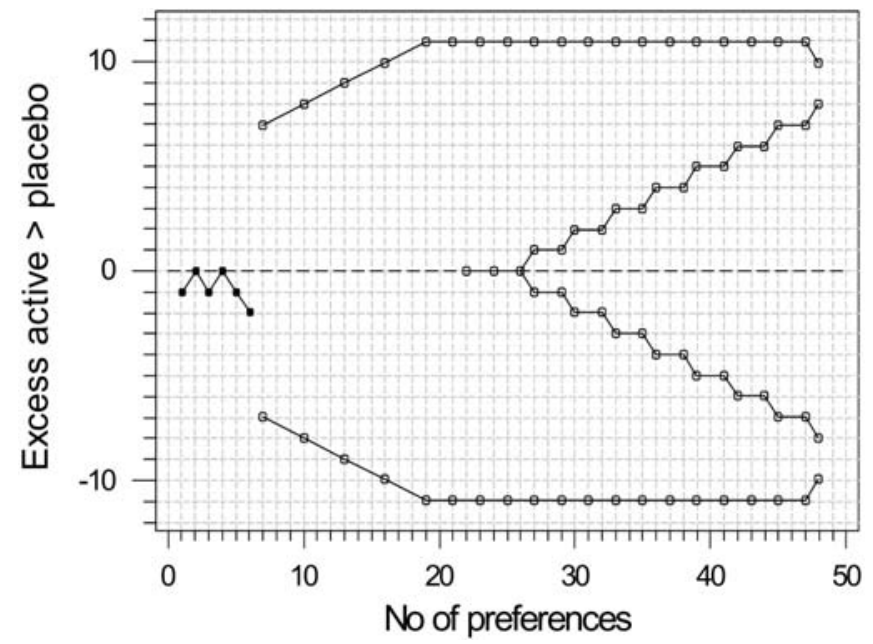

Fig. 1 Hypogastric nerve block (Bross plan A)

bringing rapid pain relief as measured on the visual analogue scale.

\section{Conclusion}

This randomised, double-blind trial demonstrates how an apparently simple and effective technique, as assessed by clinical observation, failed to fulfill its early expectations when submitted to the rigors of a double-blind trial. Sequential analysis with block randomisation allowed the study to be carried out with the minimal number of patients and a halt called when it was apparent that a clinically meaningful result was unlikely and with no women left in the trial tail as the individual observation period was short. It demonstrates how important it is to rigorously assess new and apparently useful clinical procedures before they gain widespread acceptance as a useful adjunct to treatment. This highlights how important it is to report negative results of formal clinical trials before a technique is adopted by enthusiasts on the basis of clinical experience and to avoid the risk of a publication bias of positive results.

Acknowledgements We are extremely grateful to all the women who agreed to take part in the study, complete the relevant forms and remain blinded as to the treatment that they received until the completion of the trial, and to the nurses at the Runnymede Private Hospital and St. Peter's Hospital Chertsey for their help in ensuring completion of the visual analogue scores and assessing the women's postoperative pain. We would also like to thank Dr. Andy King, anaesthetist and pain specialist, for his advice and encouragement.

\section{References}

1. Lower A (2002) Personal communication. British Society of Gynaecological Endoscopy meeting, Portsmouth

2. Whitlow BJ, Wright JT (2003) A double blind trial of hypogastric nerve block for post operative pain relief following laparoscopic excision of endometriosis. Book of Abstracts, European Society of Endoscopy and British Society of Gynaecological meeting, Glasgow 